Revista de la red interuniversitaria de estudios sobre las literaturas rioplatenses contemporáneas en Francia

Hors-série | 2019

Ricardo Piglia: Cierta idea de literatura

\title{
La experiencia rescatada: la forma del diario y "la muerte de la literatura" según Piglia
}

\section{Diego Alonso}

\section{OpenEdition}

\section{Journals}

Edición electrónica

URL: http://journals.openedition.org/lirico/7891

DOI: $10.4000 /$ lirico.7891

ISSN: 2262-8339

Editor

Réseau interuniversitaire d'étude des littératures contemporaines du Río de la Plata

\section{Referencia electrónica}

Diego Alonso, «La experiencia rescatada: la forma del diario y "la muerte de la literatura" según Piglia », Cuadernos LIRICO [En línea], Hors-série | 2019, Puesto en línea el 16 febrero 2019, consultado el 09 mayo 2019. URL : http://journals.openedition.org/lirico/7891 ; DOI : 10.4000/lirico.7891

Este documento fue generado automáticamente el 9 mayo 2019.

\section{cc) $(1) \ominus$}

Cuadernos LIRICO está distribuido bajo una Licencia Creative Commons Atribución-NoComercialSinDerivar 4.0 Internacional. 


\title{
La experiencia rescatada: la forma del diario y "la muerte de la literatura" según Piglia
}

\author{
Diego Alonso
}

\section{Lectores de sí mismos (algunas premisas)}

1 El acercamiento a una forma de la experiencia a través de la lectura no es una idea exclusiva de Piglia; se han interesado en ella autores como Cervantes, Flaubert, Kafka, Borges o T. S. Eliot, de quien proviene el epígrafe de Respiración artificial: "We had the experience but missed the meaning. And approach to the meaning restores the experience" (1988: 11). Sin embargo, la atención a ese laboratorio de escritura y registro experiencial que es el diario adquiere en Piglia una verdadera excepcionalidad que se debe examinar. Quien escribe un diario se convierte, nos asegura, en lector de sí mismo, pudiendo rescatar y conferir en ese proceso un nuevo sentido a los actos de una vida.

Empecé a escribir un diario a fines de 1957 y todavía lo sigo escribiendo. Muchas cosas cambiaron desde entonces, pero me mantengo fiel a esa manía. Por supuesto, no hay nada más ridículo que la pretensión de registrar la propia vida. Uno se convierte automáticamente en un clown. Sin embargo, estoy convencido de que si no hubiera empezado una tarde a escribirlo jamás habría escrito otra cosa. Publiqué algunos libros -y publicaré quizá algunos más- sólo para justificar esa escritura. Por eso hablar de mí es hablar de ese diario. Todo lo que soy está ahí pero no hay más que palabras. (2012: 7)

En esta forma de escritura equívocamente autobiográfica ("no hay nada más ridículo que la pretensión de registrar la propia vida"), la simple mención a la experiencia establece una dicotomía conceptualmente productiva entre la intimidad del sujeto y lo social, la identidad y la diferencia, el tiempo de la memoria y el presente histórico en que actúa. Se recordará, en este sentido, la impronta doble de la experiencia señalada por Benjamin una dimensión subjetiva, sensorial, privada (Erlebnis); y otra de carácter más tangible, transitivo, comunicable (Erfahrung)-, así como la exigencia implícita de una eventual 
articulación. La forma del diario tal como la trabaja Piglia separa el yo que vive y guarda en su interior, de manera fragmentaria y, por así decir, pasivamente, sus experiencias, de aquel que las escribe y ordena en una trama, buscando volverlas inteligibles. Al margen del protagonismo de la Erlebnis, la escritura de Piglia busca darle a la experiencia una operatividad que trascienda los límites del texto. Escribir el diario comporta un juego de máscaras, un acto cuyo sujeto, como definió bien Rimbaud en otro contexto, siempre es un Otro $^{1}$. Pero la pregunta que nos hacemos respecto a la pertinencia del concepto de experiencia inquiere no sólo sobre la condición del sujeto autobiográfico y lo que éste necesita para devenir un escritor (¿qué hacer cuando no se posee o se ha perdido la experiencia, como reconoce Piglia desde las primeras páginas del diario de Renzi?) ${ }^{2}$, sino que conlleva también una reflexión sobre el estado de la literatura y su definición en un momento determinado del proceso social. Una primera hipótesis sería, entonces, que la conciencia de la pérdida de la experiencia, así como los desplazamientos y desdoblamientos que produce en el sujeto, abre nuevos cauces al pensamiento crítico y, en particular, a la formulación de una poética. Como es sabido, para Benjamin la pobreza constatada en la "barbarie" moderna que suma al naufragio de la experiencia la pérdida del aura, se convierte en un disparador de innovaciones estéticas que, más allá de ratificar el aislamiento del individuo, hacen visible, igualmente, su condición social ${ }^{3}$. Según Benjamin: el proceso que acarrea el fin del arte de narrar crea las condiciones que hacen "perceptible, en su desaparición, una nueva hermosura" (1970: 192).

El desplazamiento de la experiencia hacia la práctica de la lectura que motiva la forma del diario tal como la entiende Piglia, lleva a reconsiderar la cuestión de la especificidad literaria. Dicho de otro modo, la reformulación del vínculo entre la literatura y la vida, implica un retorno a la pregunta inicial de la crítica moderna sobre la autonomía: ¿Qué es la literatura y cuál sería su relación con los campos discursivos y series sociales externos a ella? Conviene saber que la pregunta sobre la existencia de una especificidad propia a la literatura es respondida negativamente por Piglia, sin disipar por ello ciertas zonas de tensión. En un ensayo titulado "El escritor como lector" (Antología personal), glosa una conferencia pronunciada en Buenos Aires por Gombrowicz en 1947 y suscribe a la idea de que la especificidad literaria no depende "de una diferencia interna ni una esencia" (2014: 89). No habría, como había propuesto Jakobson, una propiedad distintiva del lenguaje poético, algo que permita hablar de la literaturidad del texto literario, sino modos de leer que varían según las contingencias recordándonos el anclaje histórico de la literatura, así como también su relativo y saludable desfase. La crítica de un texto ha de mirar por lo tanto más allá de su inmanencia y, en lo que concierne el diario de vida, más allá de la intimidad del sujeto, para examinar las tramas sociales que condicionan su valorización estética. Se invita a reflexionar de esta suerte sobre la exterioridad del texto a partir de las formas mismas y la conversión de su dimensión simbólica (no necesariamente lingüística) en metáforas ${ }^{4}$. Pues como reconoce Piglia:

[E]l valor no es un elemento interno, inmanente, sino que hay una serie de tramas sociales previas sobre las cuales el artista debe intervenir. $Y$ esas tramas definen lo artístico. Por eso, a menudo la práctica consiste en construir la mirada artística al mismo tiempo que la obra [...]

La forma no sería sólo un rasgo clave de la obra de arte, sino una categoría privilegiada de la experiencia artística (2014: 91).

Resulta útil, en este sentido, volver a pensar el doble registro de la experiencia individual y colectivo - señalado por Benjamin y cómo se manifiesta en la escritura "privada" del diario, determinándola aunque más no fuera de modo contradictorio. El 
carácter íntimo que Gombrowicz vindica para su diario esconde mal una tensión que sólo puede ser resuelta, es decir, articulada de manera lógica, mediante una dialéctica que conduzca del entendimiento ontológico (la experiencia saboreada en soledad) a la explicación (puesta en relieve del valor social de las formas en que ésta se comunica). Nuevamente: se trata del tránsito de lo simbólico e inarticulado de las formas a lo metafórico de la palabra que abre otro tipo de comprensión y, como pensaba Aristóteles, de percepción de lo semejante. Piglia no rehusaría esa dialéctica cuando constata, dicho sea de paso, en sintonía con el concepto de literatura menor articulado por Deleuze y Guattari, que:

[E]l Diario de Gombrowicz está unido al exilio, a la desposesión. El Diario es el resultado de esa desposesión: el anti-Gide, el anti-Bioy Casares. Ninguna renta, ninguna propiedad territorial. El diario define su poética. "Mi diario quiere ser lo contrario de la literatura comprometida, quiere ser literatura privada".

Lo privado en Gombrowicz es el centro de su poética. Y a la vez no hay nada menos privado que ese Diario. En Gombrowicz lo privado es un espacio de tensión con el mundo, centrado en una idea antisentimental de la vida personal. Mantenerse siempre a distancia, ser el observador de sí mismo y de los otros, no permitir nunca que nadie se acerque demasiado. (2014: 95)

5 Sintetizando lo anterior, Piglia trasciende en su idea y escritura del diario de vida una hermenéutica de sesgo romántico concentrada en una apreciación sólo ontológica de la experiencia. En todo momento busca poner de manifiesto el vínculo que une lo individual a lo colectivo a partir de una lectura adecuada de las formas. El acto solitario de la lectura, en el que se cifra la esperanza de restitución de un sentido, revela en el diario personal las tensiones planteadas por las distintas tramas sociales. El Diario de Gombrowicz resulta aleccionador al respecto; en él encuentra:

[P]equeños experimentos con la forma y la experiencia, que van y vienen de su obra a su vida. El Diario es eso, una suerte de experimentación continua con la experiencia, con la forma, con la escritura [...] Y es uno de los grandes documentos de lo que podemos llamar el escritor como lector. Porque es también la historia de sus lecturas, de esos pocos libros que conseguía por azar, de los cuales hace un uso extraordinario, y en ese sentido es, yo diría, una obra única, quizá su obra mayor.

(96)

6 Frente a aquellas voces que claman el fin de la literatura, desdibujando la distancia que existe entre ésta y los demás campos discursivos, se puede decir (segunda hipótesis) que la escritura del diario según Piglia propicia una dialéctica que convierte la búsqueda de la experiencia vital en afirmación de una experiencia estética que, obviamente, no está separada de lo social. Se plantea de este modo un problema que ha acompañado a la crítica desde la declinación del movimiento formalista y al cual Piglia no ha dejado, ni directa ni indirectamente, de referirse. Me refiero a las distintas formas de intercambio y mediaciones que relacionan la serie literaria con las otras series sociales. Prueba de este interés es su alto aprecio de Tynianov y, en particular, de su ensayo sobre "La evolución literaria", que Tynianov escribe en 1927, marcando la superación de la inmanencia programática propia del formalismo.

7 Se desprende de la teoría de Benjamin que la experiencia (en este caso, referida como Erfahrung) acarrea una fuerza política al hacer depender su existencia de la comunicabilidad, esto es, de su capacidad de transmutarse en un relato que haga visible una moral de la historia o épica de la verdad. Como ya se ha explicado, tal dimensión comunicativa se habría perdido con el auge tecnológico y, sobre todo, con el desarrollo de una nueva forma de la comunicación: la información ${ }^{5}$. Sin embargo, este retraimiento 
hacia un dominio puramente privado de la experiencia (Erlebnis) no excluye una proyección de lo individual en lo social. La negatividad que conlleva la modernidad retrae al individuo que convierte las prácticas más solitarias en afirmación de sí, pero también, al mismo tiempo, despierta una conciencia sobre el proceso social en curso y las nuevas modalidades estéticas. En el desplazamiento de la atención hacia el acto de la lectura, Piglia recoge la aporía o desafío lógico de Benjamin; pues será en este acto detenido y aislado, espejo de la memoria de Otro, que señala la posibilidad de rescatar una experiencia, condición primera de toda comunicación:

Recordar con una memoria extraña es una variante del tema del doble pero también es una metáfora perfecta de la experiencia literaria.

La lectura es el arte de construir una memoria personal a partir de experiencias y recuerdos ajenos. (2000: 53)

Se produce así una relación paradójica con la diferencia en la que el sujeto debe adoptar la identidad de otro para poder contar su propia experiencia sin convertirse en clown. Ése es, por supuesto, el valor intrínseco del bovarismo que ha dado luz a algunos de los personajes más notables de la literatura mundial. Pero también es el caso de Renzi, que, en "Notas en un diario (1987)" (Antología personal), advierte sobre la imposibilidad de comunicar la experiencia en forma directa y las ventajas de ello: "Nadie puede decir nada sobre sí mismo, pero sobre otro, es posible, quizá, en ciertas condiciones pre-ver lo que vendrá, como quien dice desatar el nudo que ata el sentido" (2014: 253). Por eso, naturalmente, dice Renzi preferir los inicios de su diario en los que la ausencia de hechos vividos le permite concentrarse en el hallazgo de formas que abran nuevos horizontes de comprensión.

En "Modos de narrar" (Antología personal), Piglia propone una genealogía del arte narrativo que destaca el viaje y la investigación o proceso de desciframiento como las matrices de todos los relatos que vendrán. La idea proviene de la Poética de Aristóteles y, en particular, de su concepto de trama vinculado con la peripetia y la anagnorisis. Estos dos movimientos se relacionan con la cuestión de la experiencia, que interesó tanto a Benjamin, y que antes había sido definida por San Agustín como la memoria de lo vivido. Se debe retener que no son los hechos en sí mismos sino la memoria de ellos lo que cuenta aquí.

Se entiende que, aunque la memoria es del pasado, como sostenía Aristóteles, el diario se narra en presente. El tiempo del diario de vida es siempre el presente, siendo la revisitación de lo vivido aquello que devuelve la experiencia. Desde esta perspectiva, el análisis se confronta con cierta relatividad ya que el rostro que aguarda al final del proceso autobiográfico no depara una verdad unívoca. Contrariamente a una biografía rica en historias, se hacen visibles sobre todo los tanteos de la exégesis; un modelo que conduce tanto a Aristóteles como a San Agustín.

11 Por último, respecto a la temporalidad, Piglia habla del diario a través de Renzi como un relato cuyo rasgo distintivo está dado por la separación cronológica de los fragmentos. "No hay otra cosa que pueda definir un diario, no es el material autobiográfico, no es la confesión íntima, ni siquiera es el registro de la vida de una persona, lo define, sencillamente, dijo Renzi, que lo escrito se ordene por los días de la semana y los meses del año" (2016: 7). El tiempo del diario es el "tiempo personal", a saber, el tiempo de la memoria que, para decirlo en el estilo de Benjamin, se consume al hilo de las lecturas donde anida la experiencia. En cuanto al nombre que da vida al diario, éste sólo "asegura la continuidad y la propiedad de lo escrito" (Piglia 2016: 8). 


\section{Emilio Renzi lector del Che} adepto de la escritura del diario, a quien distingue como el "último" lector ${ }^{6}$. ¿Qué puede significar ese adjetivo cuando se considera que la experiencia intensa del guerrillero, su vida de acción y su mirada política, se entrelazan con la subjetividad y el solitario detenimiento del lector?

El ensayo parte de una escena memorable por su patetismo que, por otra parte, ya había sido retenida por Cortázar en su cuento "Reunión". Al iniciar la gesta cubana, el Che, herido de bala, recuerda un relato de Jack London, "Encender un fuego" ("To Build a Fire"), en que el protagonista perdido en la inmensidad inhóspita de Alaska "se dispone", como luego recordará el mismo Che en Pasajes de la guerra revolucionaria, "a acabar con dignidad su vida" (citado en Piglia 2014: 264). En esa vieja lectura, Guevara encuentra una respuesta literaria a su condición actual. Habría bastante que decir sobre los diferentes usos que hacen Cortázar y Piglia de esa escena y sus derivaciones estético-políticas, pero lo que se necesita retener por ahora es el modo en que esta referencia permite relacionar la literatura a la vida, ilustrando cómo la lectura confiere sentido a lo vivido.

En esa imagen que Guevara convoca en el momento en que imagina que va a morir, se condensa lo que busca un lector de ficciones; es alguien que encuentra en una escena leída un modelo ético, un modelo de conducta, la forma pura de la experiencia.

Un tipo de construcción del sentido que ya no se transmite oralmente, como pensaba Benjamin en su texto "el narrador". No es un sujeto real que ha vivido y le cuenta a otro directamente su experiencia; es la lectura la que modela y transmite la experiencia en soledad. Si el narrador es el que transmite el sentido de lo vivido, el lector es el que busca el sentido de la experiencia perdida. (264-265)

Este núcleo argumentativo del ensayo de Piglia es repetido igualmente en otra imagen; esta vez, una fotografía en la que el Che, encaramado sobre un árbol, aislado del grupo guerrillero, lee solitario en una pausa de la guerra.

tensiones que suponen estas dos imágenes - tensiones entre la literatura y la vida, el individuo y el grupo, la ficción y la política- deberían permitir adelantar nuestro argumento. Por lo pronto, habría que señalar la continuidad, pero también un desvío, respecto a la teoría de Benjamin sobre el fin de la experiencia: el Che, quien encarna de modo excepcional la experiencia misma, epítome de una vida épica, se retrae contradictoria, paradójicamente podría decirse, en la lectura. La imagen del Che como lector opera como una metáfora para significar la distancia que separa al individuo de la vida pública y, más aún, de la vida de acción, al no corresponder con el marco donde se realiza (Piglia 2014: 267). En palabras del Che, el acto de leer es presentado como un "escape [...] de los problemas cotidianos" (citado en Piglia 2014: 266), lo cual se interpreta "como un resto del pasado, en medio de la experiencia de acción pura" (267).

Podría pensarse que Piglia habla del Che para hablar de sí mismo, de lo que le sobra y de lo que no tiene, compensando la falta. Como si dijera, "yo soy Otro; el Che que les voy a contar es mi propio simulacro". Ejercicio de autofiguración o ficcionalización de sí que deja constancia de tensiones constituivas a una escritura que mantiene una relación extrema con lo intelectual, dejando muy poco lugar para el registro autobiográfico ${ }^{7}$. Otra manera de decirlo: una escritura, la de nuestro autor, donde el material autobiográfico se 
habría motivado en la autoreferencialidad o, más precisamente, en la práctica intertextual y ficcionalización de la teoría que serían dos principios constructivos fundamentales de la literatura pigliana. El Che ofrece en este sentido una imagen compensadora que media entre la práctica solipsista y privada de la lectura, ese "vicio sin castigo" ("vice impuni") como lo llamaba Valery Larbaud, y la vida de acción que, como se deduce de las memorias de Renzi, ejerce una atracción ambivalente.

La relación entre la literatura y la vida y, más aún, entre la literatura y la política no deja de plantear problemas incluso desde antes de la incipiente autonomización de la institución literaria argentina hacia fines del siglo XIX. Para Piglia, como para muchos de sus coetáneos (verbigracia, Cortázar y Walsh para citar dos casos extremos), las dificultades que produce la reunión de estos dos campos es inevitable. En esto, el Che conoce la misma experiencia que dos figuras tan distantes como Sarmiento y el recién mencionado Walsh, quienes para operar eficazmente en el escenario político deben abandonar su condición de autores. "De hecho", escribe Piglia, "en un sentido, el político triunfa donde fracasa el escritor y Guevara tiene clara esa tensión" (272). También, en la otra dirección, la situación se vuelve compleja para el político que ha conocido el encanto de la literatura: "El escritor fracasado que renace como político intransigente, casi como no-político, o al menos como el político que está solo y hace política primero sobre sí mismo y sobre su vida y se constituye como ejemplo" (273). Piglia no ignora las limitaciones del voluntarismo revolucionario y presenta un retrato del Che como políticoartista, es decir, como un anti-político: aquél que subsume la política en su subjetividad. Reverso perfecto del ejemplo de Gramsci, oposición a la que me referiré más adelante, habría en el punto de partida y, luego, en cada uno de los pasos del guerrillero heroico el lector que busca trascender las fronteras entre la literatura y la vida, dando cuenta de un conflicto que supuestamente habría podido apaciguar.

Hay una tensión prepolítica en la búsqueda del sentido y la experiencia en Guevara. Pero a la vez podríamos decir que ha llegado hasta ahí porque ha resuelto ese dilema. De hecho, ha llegado hasta ahí también porque ha vivido su vida a partir de cierto modelo de experiencia que ha leído y que busca repetir y realizar. (265)

La simple mención de esta tensión obliga a reconsiderar el problema de la especificidad literaria y su resolución. Más allá de lo afirmado en relación a Guevara, quien aunque en algún momento ha querido ser un escritor ha cancelado esa vocación, su caso encierra una dificultad mayor. La búsqueda del Che se superpone al recorrido de algunas vanguardias estéticas que, en su objetivo de ir hacia la vida y la experiencia pura, concluyen sosteniendo la muerte de la literatura. No es casual, entonces, que su trayectoria juvenil y aventurera sea asociada en el ensayo que comentamos a los postulados de la Beat Generation. Y aunque es claro que Piglia no subscribe a esta idea de la superioridad de la vida sobre la literatura, reconoce la vigencia de esa tensión y la necesidad de revisar el concepto mismo de experiencia. Ante una pregunta que se le hace en Princeton sobre "la muerte de la literatura" ("Conversación en Princeton", Crítica y ficción), Piglia recuerda, independientemente del tono asertivo de su negación, cuántos escritores admirados se han perdido en esa búsqueda:

Por supuesto estoy en contra de esa posición, en el sentido de que para mí es mucho más interesante la literatura que la vida. Primero porque tiene una forma mucho más elegante, y segundo porque es una experiencia mucho más intensa. Para mí la literatura es una de las experiencias más intensas que conozco, sobre todo en esta época, en la que habría que ver qué debe entenderse por "la vida" [...] Entonces la muerte de la literatura es a menudo un sacrificio que ciertos extraordinarios 
escritores han hecho en beneficio de algo para lo cual la literatura no sería sino el acceso. (2001: 172)

El paralelo que traza con el Che no deja de ser notable para un escritor que deslinda tan claramente los campos en cuestión. Como él, Guevara ha comenzado a llevar un "cuaderno manuscrito" donde anota sus lecturas y, junto a éstas, aparece como consecuencia casi natural el diario personal:

Hay otra serie larga, entonces, que acompaña toda la vida de Guevara y es la escritura. Escribe sobre sí mismo y sobre lo que lee, es decir, escribe un diario. Un tipo de escritura muy definida, la escritura privada, el registro personal de la experiencia. Empieza con un diario de lecturas y sigue con el diario que fija la experiencia misma, que permite leer luego su propia vida como la de otro y reescribirla. (2014: 271)

Se ha indicado ya que para Piglia lo importante cuando se escribe un diario es separar, como lo hace Guevara, el sujeto que vive y anota sus historias de aquél que las reescribe, pues allí se instala una distancia que da otra dimensión a la experiencia perdida y permite comunicarla, reconociendo la adversidad presente. El yo que escribe es siempre un Otro, un "hueco" que debe ser llenado y en ese desplazamiento se define el estilo, la categoría acaso menos definible de la teoría literaria. En "Una propuesta para el próximo milenio" ( Antología personal), Piglia lo dice así: "El estilo sería ese movimiento hacia otra enunciación, una toma de distancia respecto a la palabra propia” (2014: 123). La lección de la experiencia no es inmediata y necesita de esa forma de extrañamiento o mediación que da la lectura. "La vida se completa con un sentido que se toma de lo que se ha leído en una ficción" (2014: 264). En una fórmula: "La verdad tiene la estructura de una ficción donde otro habla" (124). Se sabe, después de Freud, que uno siempre es hablado por otro; de allí que para Piglia La interpretación de los sueños sea un gran texto autobiográfico.

21 La visión que tiene del che como doble suyo, alguien que lee, registra sus lecturas y quiere o ha querido ser escritor, requiere una interpretación trabajosa sobre su pensamiento y práctica política. Toda la lectura del Che revolucionario se sostiene, piensa Piglia, sobre un énfasis en el individuo héroe y un voluntarismo que troca la política (el análisis de las condiciones y contingencias) por el culto al guerrillero heroico (la subjetividad). El contraste con Gramsci, como se indicaba más arriba, no puede ser mayor; por un lado, se tiene al político que funda su análisis en una atenta y equilibrada mirada exterior que le permite desarrollar las categorías de hegemonía y bloque histórico; por el otro, el guerrillero que subraya la importancia de la determinación individual. En cuanto a la visión que tiene Guevara sobre el funcionamiento político y social del arte habría poco que decir ya que sus propósitos están teñidos de un determinismo que lo lleva a juzgar el arte producido en la sociedad capitalista de naturaleza "decadente", como un reflejo de "la angustia del hombre enajenado" (1986: 322)8. Huelga decir que Piglia descree en consecuencias tan directas y parte de la premisa de que la función social y política del arte y de la literatura ocurre y debe ser leída a través de una serie de mediaciones.

He mencionado la relación que Piglia establece, retrato del Che mediante, con Cortázar, un escritor que entiende de manera cambiante la función política, desplazándose de la defensa de la libertad de creación a un compromiso ideológico que sitúa mayormente en el discurso autorial y la elección temática. Piglia ha sugerido más de una vez sus diferencias con Cortázar en relación al vínculo estético-político ${ }^{9}$. No obstante, en consideración del cuento que éste escribe sobre el Che ("Reunión"), vale notar la observación coincidente que ambos escritores hacen sobre su actividad como lector y el modo en que integra la experiencia. Cortázar llama la atención, a partir de un 
acercamiento ficcional, imaginativo, de los escritos de Guevara y su actuación en la guerra revolucionaria, sobre la importancia que revisten la máscara y el sueño en el procesamiento de la experiencia. La epifanía que celebra la supervivencia del líder de la revolución (o sea "Luis", que es Fidel) después del accidentado desembarco del Granma ocurre entre las sombras de un sueño; una visión en la que nadie puede asumir la máscara de éste o, en el sentido etimológico más apropiado, su persona. Esa visión es seguida en el cuento por una evocación que hace el Che de una melodía del cuarteto de Mozart La caza que se confunde, en perfecta armonía, con la contemplación del dibujo caprichoso que hacen las copas de los árboles: "trasposición de una ceremonia salvaje a un claro goce pensativo" (Cortázar 1977: 60). En esta ficción, fuera de sus declaraciones razonadas y explícitas, Cortázar, al igual que lo hace Piglia en su ars poética y en su obra crítica, indica el valor de las formas simbólicas como puerta de acceso a una comprensión inefable de la vida.

\section{La revisitación de “El Aleph”}

Concluía la sección anterior indicando el carácter simbólico, intuitivo, de la experiencia estética; pensada ésta como un sueño lúcido y deliberado al que el lector se abandonaría ${ }^{10}$. Regreso a esa zona íntima donde las formas remiten a estructuras profundas del inconsciente. Más allá de la incidencia que tienen las tramas sociales sobre las formas, éstas remiten a una zona secreta e inefable de la creación.

Lo que se fija en la memoria no es el contenido del recuerdo, sino su forma. No me interesa lo que puede esconder la imagen, me interesa sólo la intensidad visual que persiste en el tiempo como una cicatriz. Me gustaría contar mi vida siguiendo esas escenas, como quien sigue las señas en un mapa para guiarse en una ciudad desconocida y orientarse en la multiplicidad caótica de las calles, sin saber muy bien adónde quiere llegar. Sólo busca en realidad conocer esa ciudad, no ir a un lugar determinado, incorporarse al torbellino de tráfico para poder alguna vez recordar algo de ese lugar. (Piglia 2015: 19)

Ese sería el valor ontológico del relato autobiográfico, es decir, el rescate literario de una experiencia que da lugar a un entendimiento sin explicación: la promesa de una orientación dentro de la pluralidad y el caos de la vida. El desafío del crítico sería, en cambio, conducir esa dimensión simbólica hacia un lenguaje metafórico que una el entendimiento de las formas y su explicación. Parafraseando a Ricoeur: se trata de reunir estos dos actos, entender y explicar, en un mismo procedimiento hermenéutico.

En una época teñida por matices crepusculares en los que las fronteras entre los géneros y los campos discursivos tienden a desdibujarse, la pregunta sobre la especificidad literaria adquiere una relevancia que, si bien Piglia la cuestiona en estos términos (como se ha visto para él no hay un elemento fijo que confiera la literaturidad a un texto), relegándola a las maneras de leer, no deja de plantéarsele en el ejercicio de la escritura. Como él mismo reconoce, la naturaleza lingüística de la literatura la obliga a volverse sobre sí misma (Piglia 2014: 89)11. Para evitar el cierre de una respuesta puramente negativa, propongo volver a la lectura que hace de la figura del Aleph de Borges: una figura, se concederá, que se presenta como metáfora de la literatura y, a la vez, encierra una superación paradójica de sus propias imposibilidades. Motivada en una reflexión sobre la mímesis y las limitaciones representativas inherentes al lenguaje (una parodia descarnada de las pretensiones totalizadoras de Daneri, quien pretende en su magnum 
opus registrar todos los datos del planeta), la invocación de esta figura encierra un comentario sobre los alcances de la lectura ${ }^{12}$.

No es inopinado entonces que Piglia inicie su libro sobre la lectura, El último lector, con una reescritura de esta ficción de Borges. En el "Prólogo", donde se vuelve a contar la historia, la visión que espera al narrador está invertida como en un sueño donde lo espera, nos dice, algo "más real que la realidad, más indefinido y más puro" (2005: 16). Este Aleph, obra de un fotógrafo llamado Russell, es la "replica" o reducción esencial de una ciudad olvidada, ya transformada en el tiempo y recuperada gracias a la lectura. Quisiera recalcar que la relación con la lectura está claramente establecida y que la percepción de ese objeto, como ocurre en el cuento de Borges, sólo puede efectuarse individualmente, en la "intimidad" y el "aislamiento" (12). La literatura sería definida así como el mapa de una ciudad perdida; la posibilidad de acceder a una realidad que el lector debe descifrar, aventurándose en pos de una promesa.

La ciudad trata entonces sobre réplicas y representaciones, sobre la lectura y la percepción solitaria, sobre la presencia de lo que se ha perdido. En definitiva trata sobre el modo de hacer visible lo invisible y fijar las imágenes nítidas que ya no vemos pero que existen todavía como fantasmas y viven entre nosotros. (13) ${ }^{13}$

La experiencia resultante es por supuesto de orden estético y como tal nos confronta con lo indefinido e indeterminado; se produce entre lo real y lo imaginario, entre la certeza de la recuperación y el extrañamiento de la pérdida. Su sentido, como si se tratase de una música perfecta, nos llega liberado de lo referencial entre la confusión de los ruidos del mundo ${ }^{14}$.

La dificultad moderna de situar una experiencia y hacerla comunicable a través del habla conduce al individuo aislado a transitar otras sendas que le permitan recuperar los sentidos perdidos. La indeterminación que rodea esta búsqueda, habiéndose cancelado la dimensión épica de la verdad, sería la misma que caracteriza la literatura moderna. En palabras de Blanchot, interesado en definir el concepto de experiencia:

Quien se consagra a la obra es atraído hacia el punto en que ésta se somete a la prueba de su imposibilidad. En este sentido, es una experiencia, pero, ¿qué quiere decir esta palabra? [...] Aquí, experiencia significa: contacto con el ser, renovación de sí mismo en ese contacto; una prueba, pero una prueba que permanece indeterminada. (2002: 75)

Los hallazgos que la literatura depara no se traducen luego en consejos.

Como observa Foucault en una conferencia cuyo tema es, precisamente, la especificidad de la literatura, una vez desaparecida la palabra absoluta de la época clásica y caducadas las formas retóricas que dictaban las normas hasta el siglo XVIII, puede surgir la literatura como substitución de aquellos lenguajes anteriores que ignoraban la indefinición y negatividad. "A partir del siglo XIX se deja de estar a la escucha de esa primera palabra y, en su lugar, se hace oír el infinito del murmullo, el amontonamiento de palabras ya dichas..." (2015: 92). En esta selva de voces, que define tan bien la narrativa de Piglia (recordemos la mente del Gaucho Dorda en Plata quemada), se abandona la idea de transmitir un saber o inculcar una verdad, aunque persista la pregunta sobre el tipo de experiencia que espera al lector de literatura. Asimismo Borges, refiriéndose al "centro inefable" de su relato, apunta en esa dirección: "Todo lenguaje es un alfabeto de símbolos cuyo ejercicio presupone un pasado que los interlocutores comparten; ¿cómo transmitir a los otros el infinito Aleph, que mi memoria apenas abarca?" (1974: 621). Una pregunta análoga se hace la literatura respecto a la experiencia. 
31 En uno de los más lúcidos ensayos sobre "El Aleph", Maurice Blanchot explica (aunque quizá éste no sería el verbo más apropiado) el sentido de la figura que da nombre al cuento. En tanto emblema de lo literario, esta figura sería portadora de una negatividad "el infinito malo" ("le mauvais infini"), dice Blanchot recordando a Hegel- que, a su vez, define la experiencia del lector. Como el concepto de eternidad, que Borges asocia al artificio y a la apreciación exclusiva de los sentidos, el infinito sólo es un efecto literario que postula una relación improbable. Pues como sostiene Blanchot, la literatura no sería la negación de lo real sino la posibilidad de un hallazgo ${ }^{15}$. Borges ha insistido en este concepto de la literatura como promesa de una comprensión. Sólo la experiencia estética puede trascender el caos del mundo o, si se prefiere, el exceso al que nos confronta la espesa selva de lo real. El anhelo de ordenar ese exceso no se abandona, pero como Piglia hace saber, ni Borges ni él nos dirán cuál es el orden infructuosamente buscado. Sólo queda la promesa de una comprensión encerrada en un falso infinito y una falsa eternidad.

Regresando al argumento de Foucault, la literatura moderna (la única digna de ese nombre) emerge con un lenguaje anterior, ya constituido a sus espaldas; un lenguaje que ella repite y borra, transgrede, profana y vuelve simulacro, hasta captar lo que sería su verdadera esencia. Ella encuentra su especificidad, entonces, a través de una lengua que se abre paso entre los restos de una tradición y resiste, por otra parte, al imperativo de la re-presentación. Es en la búsqueda de una "blancura esencial donde nace la pregunta ¿Qué es la literatura?" (Foucault 2015: 76). Acaso por ello puede conjeturarse que Borges, en la postdata agregada a su cuento, sugiere que el verdadero Aleph, aquél que ahora sí sería una metáfora perfecta de la literatura, es el Aleph secreto que está en el corazón de una de las columnas de la mezquita de Arm, en el Cairo; un Aleph que nadie puede ver, pero que deja oír el "atareado rumor" del universo.

Vemos así una continuidad entre la poética de Piglia y la propuesta de Borges de considerar la literatura y todo "hecho estético" como un trabajo formal conducente a una comprensión por siempre inarticulada o, como recordamos antes, la "inminencia de una revelación, que no se produce" (635). Para él, como para el autor de Ficciones, la comprensión que promete la literatura - ese suplemento de sentido que nos devuelve la experiencia extraviada- es de carácter intuitivo. Por ello, si bien sus formas remiten a núcleos del funcionamiento social, esto no autoriza a confundir la literatura con los discursos exteriores a ella ${ }^{16}$. Su sentido no se agota en una traducción que no sabría disipar el extrañamiento que produce. Y así lo precisa Piglia en "Notas en un diario (1987)": "Encontrar por fin una forma perfecta que no tenga final, que sólo lo anuncie (como en los relatos de Kafka). Una forma cerrada, que remita de un punto a otro de la estructura, un relato lineal que sin embargo funcione como un juego de espejos, o una adivinanza circular" (2014: 257). Una forma cuya significación sólo se anuncie y remita a hallazgos anteriores (otras lecturas) en un muy borgeano juego de espejos que se desplazan.

A modo de conclusión: en línea con la teoría de Benjamin, para Piglia el narrador comunica su experiencia libre de explicaciones, acercándose así a un punto esencial del arte literario ${ }^{17}$. De igual manera, en el diario de vida la escritura se presenta como un ejercicio abierto a la indeterminación y al olvido o memoria imperfecta, y no como documento de los hechos vividos. Se narra la búsqueda y no el hallazgo de la experiencia. Volviendo a la distinción de Benjamin, opera la Erlebnis, la experiencia interior, intransmisible de modo directo, y no la Erfahrung que se asocia con una épica de la 
verdad. Para Renzi, la forma del diario se disimula detrás del pretexto autobiográfico orquestado alrededor de la experiencia como elemento ausente que la lectura promete restituir. Mas como él lo dice al iniciar su diario, "[e]l valor de la lectura no depende del libro en sí mismo, sino de las emociones asociadas al acto de leer. Y muchas veces atribuyo a esos libros lo que corresponde a la pasión de entonces (que ya he olvidado)" (2015: 19).

El diario notifica y piensa las contradicciones que marcan el encuentro entre la subjetividad y la experiencia, así como entre el individuo y su sociedad. Más aún, según he tratado de mostrar, se reafirma en él el valor de la experimentación formal como núcleo de una poética que no deja de pensar su propia condición (¿Qué es la literatura?), su relación con la vida y la definición de la experiencia. Teniendo como premisa la imposibilidad moderna de transmitir una experiencia, lo cual trae aparejada la muerte del narrador, el diario abraza una indefinición que sería propia de la literatura, sin dejar de pensar por ello en las mediaciones que la ligan a su exterior. Ese sería el reto de una escritura en que la subjetividad puede ser trascendida.

\section{BIBLIOGRAFÍA}

Aristóteles, Poética, Buenos Aires, Colihue, 2009. Traducción de Eduardo Sinnott.

Benjamin Walter, "El narrador. Consideraciones sobre la obra de Nicolai Leskov", Sobre el programa de la filosofía futura y otros ensayos, Caracas, Monte Ávila Editores, 1970, p. 189-211. Traducción de Roberto J. Vernengo.

Blanchot Maurice, El espacio literario, Madrid, Editora Nacional, 2002. Traducción de Vicky Palant y Jorge Jinkis.

--- "El infinito literario: El Aleph", El libro por venir, Madrid, Editorial Trotta, 2005, p. 122-125. Traducción de Cristina de Peretti y Emilio Velasco.

Borges Jorge Luis, "El Aleph", Obras completas, Buenos Aires, Emecé Editores, 1974.

Cortázar Julio, "Reunión", Todos los fuegos el fuego, Barcelona, Edhasa, 1977.

Ferris David S., The Cambridge Introduction to Walter Benjamin, Cambridge, Cambridge University Press, 2008.

Foucault Michel, La gran extranjera: para pensar la literatura, Buenos Aires, Siglo Veintiuno Editores, 2015. Traducción de Horacio Pons.

Guevara Ernesto, "El hombre nuevo", Ideas en torno de Latinoamérica, Volumen 1, México D.F., Universidad Autónoma de México, 1986, p. 313-327.

Piglia Ricardo, Respiración artificial, Buenos Aires, Sudamericana, 1988.

--- Formas breves, Barcelona, Editorial Anagrama, 2000.

--- Crítica y ficción, Barcelona, Editorial Anagrama, 2001.

--- El último lector, Barcelona, Editorial Anagrama, 2005. 
--- Plata quemada, Barcelona, Editorial Anagrama, 2006.

--- y Eduardo Stupía, Fragmentos de un diario, Buenos Aires, Galería Jorge Mara-La Ruche, 2012.

--- Antología personal, México D.F., Fondo de Cultura Económica, 2014.

--- Los diarios de Emilio Renzi. Años de formación, Barcelona, Editorial Anagrama, 2015.

--- Los diarios de Emilio Renzi. Los años felices, Barcelona, Editorial Anagrama, 2016.

--- Los diarios de Emilio Renzi. Un día en la vida, Barcelona, Editorial Anagrama, 2017.

Premat Julio, Héroes sin atributos. Figuras de autor en la literatura argentina, Buenos Aires, Fondo de Cultura Económica, 2009.

Ricoeur Paul, La métaphore vive, París, Seuil, 1975.

--- Hermenéutica y acción. De la hermenéutica del texto a la hermenéutica de la acción, Buenos Aires, Prometeo Libros, 2008. Traducción de Mauricio M. Prelooker, Luis J. Adúriz, Aníbal Fornari, Juan Carlos Gorlier y María Teresa La Valle.

Tynianov J., "De l'évolution littéraire", Tzvetan Todorov (Editor y Traductor), Théorie de la littérature, París, Éditions du Seuil, 1965, p. 120-137.

\section{NOTAS}

1. En un ensayo sobre el Che Guevara, que Piglia recoge en su Antología personal y sobre el que se volverá en la segunda parte de este estudio, se observa, en coincidencia con lo indicado en el cuerpo del texto: "Escribe sobre sí mismo y sobre lo que lee, es decir escribe un diario. Un tipo de escritura muy definida, la escritura privada, el registro personal de la experiencia. Empieza con un diario de lecturas y sigue con el diario que fija la experiencia misma, que permite leer luego su propia vida como la de otro y reescribirla [...] Desde muy joven, encuentra un sistema de escritura que consiste en tomar notas para fijar la experiencia de inmediato y después escribir un relato a partir de las notas tomadas. La inmediatez de la experiencia y el momento de la elaboración. Guevara tiene clara la diferencia: 'El personaje que escribió estas notas murió al pisar de nuevo tierra argentina, el que las ordena y las pule (yo), no soy yo', escribe en el inicio de Mi primer gran viaje" (2014: 271).

2. Se lee en la "Nota del autor" al primero de los diarios de Renzi: "Al principio las cosas fueron difíciles. No tenía nada que contar, su vida era absolutamente trivial. 'Me gustan mucho los primeros años de mi diario justamente porque allí lucho con el vacío. No pasa nada, nunca pasa nada en realidad, pero en aquel tiempo me preocupaba. Era muy ingenuo, estaba todo el tiempo buscando aventuras extraordinarias', había dicho una tarde en el bar de Arenales y Riobamba. Entonces, empezó a robarle la experiencia a la gente conocida, las historias que se imaginaba que vivían cuando no estaban con él" (2015: 11).

3. Véase Ferris 2008: 111-113.

4. La mención a los conceptos de símbolo y metáfora remite al razonamiento iniciado por Paul Ricoeur a partir de La metáfora viva (1975). La inversión del orden que antes, en el análisis de Ricoeur, se focalizaba en el símbolo para luego pasar a la palabra, se justifica en la premisa de que la metáfora, al pertenecer de lleno al lenguaje (retórica), permite la articulación dialéctica de estos dos elementos constitutivos de la obra literaria. Se espera mediante dicha inversión "la clarificación de las ambigüedades, de las complejidades y de las rarezas que recargan el concepto de símbolo" (2008: 22).

5. Véase Benjamin 1970: 193-194. 
6. El ensayo, "Ernesto Guevara, rastros de lectura", fue publicado inicialmente en El último lector (2005) y, luego, recogido en Antología personal (2014) con un título algo distinto: "Ernesto Guevara, el último lector". Mis citas remiten a esta última edición.

7. Para un estudio señero de las formas de inscripción textual o autofiguración del autor, véase Premat 2009. Sobre las tensiones señaladas en este tipo de discursos ver p. 12.

8. El trabajo de Guevara que citamos se titula "El hombre nuevo" y fue originalmente escrito para el semanario Marcha de Montevideo en marzo de 1965. Véase Guevara 1986: 321-323.

9. Véase Piglia 2001: 45-49.

10. Se reconocerá en mi formulación la estructura oximorónica con que Borges se refiere a la experiencia estética, definida no sólo como el abandonarse a un sueño voluntario ("El escritor argentino y la tradición", Obras completas, 274), sino también como la participación en un juego de formas o "inminencia de una revelación, que no se produce" ("La muralla y los libros", Obras completas, 635).

11. Ante la pregunta ¿Qué es la literatura?, Foucault recuerda igualmente que ésta es una pregunta inherente a ella misma: "un hueco donde ésta tendría que alojarse y probablemente recoger todo su ser" (2015:73). La literatura, "diferente del lenguaje y diferente de la obra [...] dibuja un espacio vacío, una blancura esencial donde nace la pregunta 'Qué es la literatura', una blancura esencial que es en efecto esta pregunta. Por consiguiente, esta pregunta no se superpone a la literatura, no es el agregado de una conciencia crítica complementaria a la literatura: es su ser mismo, originariamente desmembrado y fracturado" (76).

12. La figura del Aleph como metáfora del texto en espera de su lector es propuesta por Piglia más de una vez; en “¿Qué es un lector?” define el Aleph como “el objeto mágico del miope, el punto donde todo el universo se desordena y se ordena [...] Los signos de la página, casi invisibles, se abren a universos múltiples. En Borges la lectura es un arte de la distancia y de la escala" (2005: 19-20).

13. "La lectura", recuerda Piglia que decía Pound, "es un arte de la réplica. A veces los lectores viven en un mundo paralelo y a veces imaginan que ese mundo entra en la realidad" (2005: 12).

14. En un homenaje al compositor Gerardo Gandini, Piglia elabora un contraste entre la que sería la más perfecta de las artes, la música - perfecta en el sentido de haberse liberado del peso de lo referencial y mostrar mejor que las demás su relación con la tradición-, y el contexto de la modernidad en el que surge. Ella se abre paso en medio de "una confusa profusión de sonidos inarticulados" (2000: 44) o "ciénaga de ruidos" (45). En ese contexto, la experiencia se asemejaría, concluye Piglia, a "los restos de una música que se ha perdido" (45).

15. "La literatura no es un simple engaño, sino el peligroso poder de ir hacia lo que es a través de la infinita multiplicidad de lo imaginario. La diferencia entre lo real y lo irreal, el inestimable privilegio de lo real, es que hay menos realidad en la realidad, al no ser ésta sino la irrealidad negada, apartada por el enérgico trabajo de la negación y por esa negación que es asimismo el trabajo" (Blanchot 2005: 125).

16. En este sentido debe leerse el cuestionamiento de Piglia a una crítica "progresista" que equipara la literatura a "una serie de documentos sociales que circulan con [su] mismo estatuto" (2001: 174). Cuando éste es el criterio seguido, "[l]a crítica tiende a ver la literatura como un síntoma, como un síntoma de otra cosa" (174).

17. "Cada mañana", escribe Benjamin refiriéndose a los efectos de la información, "se nos informa sobre las novedades de toda la tierra. Y sin embargo somos notablemente pobres en historias extraordinarias. Ello proviene de que ya no se nos distribuye ninguna novedad sin acompañarla de explicaciones. Con otras palabras, ya casi nada de lo que acaece conviene a la narración, sino que todo es propio de una información. Puesto que es casi la mitad del arte de narrar una historia el mantenerla ajena a toda explicación mientras se la reproduce" (1970: 194). 


\section{RESÚMENES}

Este trabajo indaga sobre el modo en que Ricardo Piglia (1940-2017) retoma el concepto de experiencia desarrollado por Benjamin en su ensayo "El narrador. Consideraciones sobre la obra de Nicolai Leskov". Haciendo suya la premisa de que la modernidad marca el ocaso de una experiencia comunicable y la declinación del arte narrativo, Piglia subraya el vínculo con la lectura como práctica constitutiva que devuelve los sentidos de lo vivido. Interesa preguntarse cómo esta categoría, la experiencia, permite esclarecer la relación indeterminada y no exenta de tensiones entre la literatura y la vida; lo cual nos lleva a considerar la importancia del diario personal, cuya escritura es dada como condición de posibilidad y clave de una literatura futura.

Ce travail explore la façon dont Ricardo Piglia (1940-2017) reprend le concept d'expérience développé par Benjamin dans son essai "Le narrateur. Réflexions sur l'œuvre de Nicolas Leskov". Faisant sienne la prémisse que la modernité marque le déclin d'une expérience communicable ainsi que celui de l'art narratif, Piglia souligne l'importance de la lecture comme pratique qui renvoie au sens du vécu. Il est intéressant de se demander comment cette catégorie, l'expérience, permet de clarifier la relation indéterminée et non sans tensions entre la littérature et la vie; ce qui nous conduit à considérer l'importance du journal intime dont l'écriture se présente comme condition de possibilité et clé d'une littérature future.

This article explores the way in which Ricardo Piglia (1940-2017) echoes the conception of experience developed by Benjamin in his essay "The Storyteller: Reflections on the Works of Nikolai Leskov". Departing from the premise that modernity marks the decline of a communicable experience and of narrative art, Piglia identifies reading as a practice that rekindles the senses of lived events. It is relevant, in that respect, to reflect upon how this concept, experience, sheds light on the fluid as well as tension-ridden relationship between literature and life. This, in turn, leads us to consider the importance of the personal journal whose writing is conceived as seminal to future literary creation.

\section{ÍNDICE}

Mots-clés: expérience, journal intime, mémoire, politique, spécificité du texte littéraire

Keywords: experience, private diary, memory, politics, literary specificity

Palabras claves: experiencia, diario de vida, memoria, política, especificidad literaria

\section{AUTOR}

\section{DIEGO ALONSO}

Reed College

alonsod@reed.edu 